\title{
Structural study of pulmonary circulation and of heart in total anomalous pulmonary venous return in early infancy
}

\author{
SHEILA G. HAWORTH AND LYNNE REID \\ From Department of Experimental Pathology, Cardiothoracic Institute, Brompton Hospital, \\ Fulham Road, London
}

Quantitative morphometric techniques have been applied to the injected and inflated lung and to the heart in 9 infants with total anomalous pulmonary venous return dying with obstruction to pulmonary venous return. In 5 (mean age at death 55 days) pulmonary venous blood drained to a supradiaphragmatic site; in the remaining 4 (mean age 20 days) to an infradiaphragmatic site.

Structural changes were present in the pulmonary circulation in all patients, even in the youngest, an 8-day-old child. In both types of total anomalous pulmonary venous return increased arterial muscularity was severe, as shown by increase in wall thickness and by extension of muscle into smaller and more peripheral arteries than normal; these changes tended to increase with age. Where the pulmonary venous blood drained to a supradiaphragmatic site, the severity of arterial medial hypertrophy correlated inversely with the magnitude of the pulmonary: systemic flow ratio, increasing as the pulmonary blood flow fell. Vein wall thickness was increased and in all but the youngest child the veins were 'arterialised'. At the lung periphery the arteries and alveoli appeared to have multiplied normally. Arterial size varied according to whether pulmonary venous blood drained above or below the diaphragm; the diameter of pre-and intra-acinar arteries was increased only in cases where the pulmonary venous return drained to a supradiaphragmatic site, being normal when it drained to an infradiaphragmatic site.

In the heart the left ventricle was of normal size in all but one case. Dilatation and severe hypertrophy of the right ventricle and septum were present only in cases of drainage to a supradiaphragmatic site.

In the older patients with the latter anomaly dilatation of the pulmonary arteries and right ventricle suggested that a large left-to-right shunt had preceded the onset of obstruction to pulmonary venous return and that the more severe right ventricular and septal hypertrophy in these cases might be the result of a longer duration of pulmonary hypertension. In contrast, in total anomalous pulmonary venous return to an infradiaphragmatic site it appears that obstruction to pulmonary venous return develops soon after birth and prevents a large increase in pulmonary blood flow, and thus neither the pulmonary arteries nor the right ventricle become dilated. In infants with total anomalous pulmonary venous return and obstruction to pulmonary venous return, it is striking how rapidly the pulmonary circulation develops new muscle.

Total anomalous pulmonary venous return is a disease of infancy (Burroughs and Edwards, 1960; Bonham-Carter et al., 1969) since fewer than 25 per cent of patients with the uncomplicated form survive infancy and these usually have a supradiaphragmatic type of connexion. They develop pulmonary hypertension in later life when high pulmonary blood flow has led to pulmonary vascular disease, a pattern of response similar to that in secundum atrial septal defect.

Received for publication 7 June 1976
Most infants with an infradiaphragmatic type of pulmonary venous connexion develop obstruction to pulmonary venous return soon after birth, but it is now recognised that also when the connexion is supradiaphragmatic, obstruction can develop at this time (Gathman and Nadas, 1970). In infancy, the operative mortality remains high. Creation of a large interatrial communication by Rashkind septostomy is said to lower pulmonary arterial pressure (Miller et al., 1967; Serratto et al., 1968) by allowing more blood to enter the systemic 
circulation. Improvement of symptoms by this procedure may allow postponement of corrective surgery until after the first year of life when surgical mortality decreases significantly (Leachman et al., 1969). The possibility that structural changes in the pulmonary circulation contribute to the high operative mortality and that incomplete relief of pulmonary venous obstruction by Rashkind septostomy could worsen such changes indicates the need for detailed information on the state of the pulmonary vessels.

The lungs of patients with total anomalous pulmonary venous return have been described as oedematous and atelectatic with dilated lymphatic channels (Kauffman et al., 1962) and thickened alveolar walls (Johnson et al., 1958), but there have been few reports on the vascular structure. Lucas et al. (1963) observed little change during the first month of life, though reporting the 'early' development of pulmonary arterial and venous medial hypertrophy in any cardiac malformation in which obstruction to pulmonary venous return is present at or soon after birth. 'Underdevelopment' of the left ventricle has been reported in total anomalous pulmonary venous return by some workers (Hastreiter et al., 1962), one of a normal size by others (Leachman et al., 1969).

In the present study quantitative morphometric techniques have been applied to the injected and inflated lung in order to determine whether the pulmonary vessels are structurally normal at birth, and to assess the effect of pulmonary venous obstruction on the early days of postnatal growth. The size, number, and wall structure of both preand intra-acinar arteries have been determined in the lungs of 9 infants with total anomalous pulmonary venous return dying within the first three months of life. The heart has also been examined in detail to assess dilatation and hypertrophy of the right ventricle and also the degree of left ventricular development.

\section{Subjects and methods}

The heart and lungs from 9 infants with total anomalous pulmonary venous return, all dying within the first three months of life, have been examined (Table 1). In 5 patients pulmonary venous blood drained to a supradiaphragmatic site-to a left superior vena cava in 3 , to the coronary sinus in 1 , and directly to the right atrium in the remaining case. In 4 cases pulmonary venous blood drained to an infradiaphragmatic site -into the portal venous system at the porta hepatis. Infants with supradiaphragmatic drainage tended to present at a slightly older age than those with
Table 1 Site of pulmonary venous drainage and age at death of cases studied

\begin{tabular}{llll}
\hline & $\begin{array}{l}\text { Case } \\
\text { no. }\end{array}$ & $\begin{array}{l}\text { Site of anomalous } \\
\text { pulmonary venous } \\
\text { drainage }\end{array}$ & $\begin{array}{l}\text { Age at } \\
\text { death }\end{array}$ \\
\hline $\begin{array}{c}\text { Supradiaphragmatic } \\
\text { total anomalous }\end{array}$ & 1 & Coronary sinus & 21 days \\
pulmonary venous & 3 & Left superior vena cava & 2 months \\
return & 4 & Left superior vena cava & 2 months \\
Infradiaphragmatic & 5 & Left superior vena cava & 3 months \\
total anomalous & 7 & Portal system & 8 days \\
pulmonary venous & 8 & Portal system & 14 days \\
return & 9 & Portal system & 1 month \\
\hline
\end{tabular}

infradiaphragmatic drainage. All infants presented with cyanosis, which was more severe in those with infradiaphragmatic drainage, and all were tachypnoeic. In cases of drainage to a supradiaphragmatic site a chest bulge and a pulmonary ejection murmur in all but case 2 suggested that pulmonary blood flow was, or had been, raised.

Radiographic findings were different in the two types of anomalous venous drainage. In cases with supradiaphragmatic drainage cardiac enlargement was prominent; measurements of the transverse cardiac diameter exceeded the normal range, the cardiothoracic ratio (expressed as a percentage) varying between 61.0 and 69.5 : dilatation of the pulmonary arteries was present in all. In contrast, in cases with infradiaphragmatic drainage the heart size was generally normal and the pulmonary arteries were not dilated. Pulmonary oedema was prominent and generalised in all cases of the latter type but was seen in only 3 cases with supradiaphragmatic drainage (cases 2,4 , and 5) and was then only slight.

\section{ELECTROCARDIOGRAPHIC FINDINGS}

The mean frontal plane QRS axis was to the right of average in all 9 cases, exceeding the 95th centile in all children aged 1 month and over (Moss and Adams, 1968). All electrocardiograms had signs of right ventricular hypertrophy with upright $T$ waves in the right praecordial leads in 7 cases and biphasic $T$ waves in 2. Right atrial $P$ waves were prominent only in electrocardiograms of patients with supradiaphragmatic drainage. In all 9 cases the amplitude of the $R$ wave in the left praecordial leads was normal.

HAEMODYNAMIC FINDINGS (Table 2)

Pulmonary arterial hypertension was severe in all 9 patients and pulmonary vascular resistance was greater than 12 units in all but case 1 , the youngest patient with supradiaphragmatic drainage. In case 
Table 2 Haemodynamic findings in total anomalous pulmonary venous return

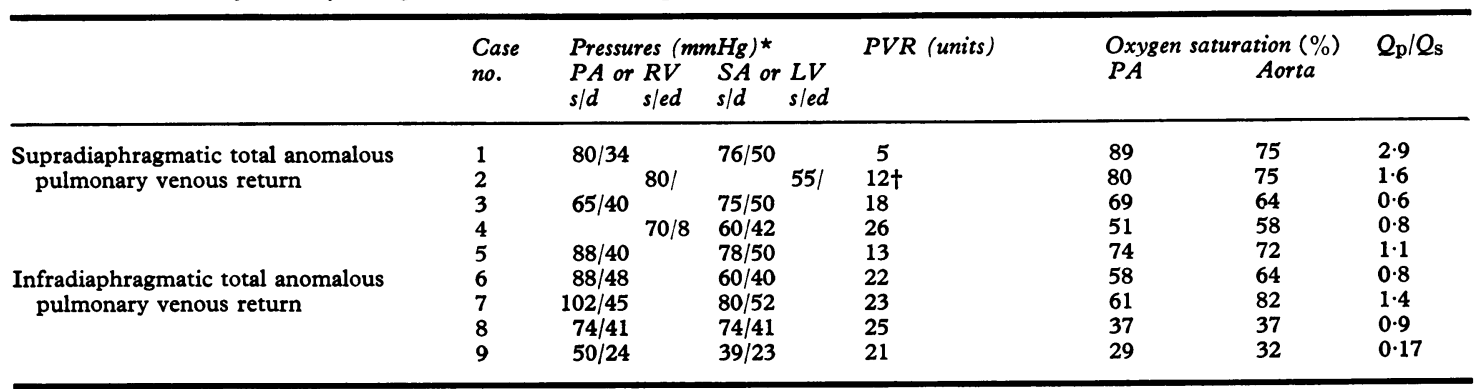

^Reference zero: mid thorax. †Pulmonary arterial diastolic pressure assumed.

Abbreviations: PA, pulmonary arterial; RV, right ventricular; SA, systemic arterial; LV, left ventricular; $Q_{p} / Q_{s}$, pulmonary/systemic flow ratio; s, d, ed, systolic, diastolic, end-diastolic.

3, external compression between the left pulmonary artery anteriorly and the left bronchus posteriorly produced a $10 \mathrm{mmHg}$ pressure gradient in the left superior vena cava.

\section{OBSTRUCTION TO PULMONARY VENOUS RETURN}

Anatomical obstruction to pulmonary venous return is frequently not apparent at necropsy. In a recent study by Delisle et al. (1976) a pulmonary arterial pressure at or above systemic level was associated with obvious anatomical obstruction of the anomalous venous pathway in 74 per cent of cases while a raised pulmonary arterial pressure that remained below systemic level was associated with anatomical obstruction in only 13 per cent. In the present study pulmonary arterial pressure exceeded systemic pressure in 7 cases, was equal in 1, and only $10 \mathrm{mmHg}$ below in the remaining case (Table 2). At necropsy in all cases of the infradiaphragmatic type, anatomical obstruction was shown at the junction of the common pulmonary vein with the portal venous system, but in only one case of the supradiaphragmatic type (case 3 ), at the junction of the left superior vena cava with the innominate vein. In 2 cases of supradiaphragmatic type the foramen ovale was small, less than $3 \mathrm{~mm}$ in diameter, and had not been crossed at cardiac catheterisation, suggesting that in these patients the foramen ovale may have been the site of obstruction to venous return to the left side of the heart. Since each patient presented as a clinical emergency and had severe pulmonary hypertension, all are assumed to have had obstruction of the anomalous venous pathway. Eight patients had surgical treatment and died either at operation or in the immediate postoperative period. The remaining case (case 9) died before it was possible to operate.

\section{Methods}

\section{I: EXAMINATION OF LUNG}

Preparation of lung tissue

In Cases $3,5,7,8$, and 9 the pulmonary arteries to both lungs were injected and in the other 4 cases the right pulmonary artery and the left pulmonary veins. A 'Micropaque'/gelatin suspension at $60^{\circ} \mathrm{C}$ was injected at a pressure of $100 \mathrm{~cm}$ of water: this injection technique distends and fills all vessels larger than $15 \mu \mathrm{m}$ in diameter. The lungs were then inflated with a buffered formol saline solution at a pressure of $45 \mathrm{~cm}$ of water and allowed to fix. Lung volume was then determined by water displacement, and each lung radiographed and sliced (Hislop and Reid, 1970; Davies and Reid, 1970), blocks of tissue being selected for microscopical examination by a random sampling technique (Dunnill, 1962).

Quantitative analysis of structural features of lung From the arteriogram the following features were assessed: hilar and intrapulmonary pattern of branching and the density of the background haze which reflects the number of small peripheral arteries (Anderson et al., 1973); apicocaudal lung length; length of the posterobasal artery measured along its pathway from hilum to costophrenic angle; lumen diameter of this arterial pathway measured at the hilum and at 25 per cent intervals from the hilum to the pleural surface.

Microscopically the following features of peripheral arterial structure were studied: the external diameter of an individual artery was measured by taking the distance between the external elastic laminae across two diameters; wall thickness was measured from external to internal elastic laminae at the four sites where the measured diameters cut 
the wall: the mean wall thickness was then calculated. From these measurements $\frac{2 \times \text { wall thickness }}{\text { external diameter }}$ $\times 100=$ per cent wall thickness. The structure of the arterial wall, whether muscular, partially muscular, or non-muscular, was established. The arteries within a unit area of lung section were grouped by size and structural type, and the proportion of each structural type within a size group determined-described as a 'population count'. Where a small artery accompanies a small airway it was also characterised by reference to the type of airway it accompanies. Thus the structure of the artery could be related to airway level and in this way extension of muscle along the arterial pathway is established. The number of arteries and alveoli were counted in the same area of lung section and the results expressed as a ratio: this made allowance for any difference in the degree of inflation in the various lungs. The proportion of lung volume occupied by various structures was established by a microscopical point-counting technique (Dunnill, 1962).

Increased arterial size was apparent from an increase in luminal diameter of preacinar arteries on the postmortem arteriogram and an increase in external diameter of intra-acinar arteries, measured microscopically. Reduction in arterial number was indicated by a reduction in density of the background haze on the arteriogram and confirmed by finding a reduction in the number of arteries counted per unit area of lung which increases the alveolar/arterial ratio. Increased arterial muscularity was apparent from an increased wall thickness as related to the size of an artery or the presence of muscle in arteries which are either smaller or in a more peripheral position along the arterial pathway than is normal. Since, in the first weeks of life, the lung is growing rapidly, the findings for each patient were compared with those of a normal infant of the same age (Hislop and Reid, 1973a, b).

\section{II : EXAMINATION OF HEART}

The inflow and outflow tracts of both ventricles and the ventricular free wall thickness were measured according to the method described by de la Cruz et al. (1960). The heart was weighed after being fixed for at least one week in buffered formol saline, Millard (1965) having shown that by this time reduction in weight because of fixation shrinkage is complete. Each heart was dissected using the method of Fulton et al. (1952) except that the free wall of the left and the right ventricle was each separated from the septum. Any papillary muscles on either side of the septum were shaved off and included with the ventricle. The ventricular and interventricular muscle was weighed in 3 parts-the right ventricle (RV), the left ventricle (LV), and the septum (S).

Hypertrophy of the right ventricle is best assessed by weight (Fulton et al., 1952). In the adult, hypertrophy of the right ventricle affects the free wall of the ventricle rather than the septum: the septum acts as part of the left ventricle and hypertrophies with it (Fulton et al., 1952). Hypertrophy of the right ventricle can thus be assessed from the ventricular weight, and from the ratio of the weight of the left ventricle and septum $(\mathrm{LV}+\mathrm{S})$ to that of the right ventricle, expressed as $L V+S / R V$. In the present study, in cases of total anomalous pulmonary venous drainage of the supradiaphragmatic type, the right ventricle was hypertrophied and the septum appeared to have hypertrophied with the free wall of this ventricle. Thus, in these cases, the ratio of $L V+S / R V$, taken alone, is an unsatisfactory method of assessing right ventricular hypertrophy, the weight of the septum and of the free wall of the right ventricle must each be considered.

\section{Results}

I : STRUCTURAL CHANGES IN LUNGS

Lung volume and length were normal in all cases. The branching pattern of the main arterial and venous pathways appeared normal. On microscopy, perivascular oedema, dilated lymphatic channels, and eosinophilic material within the alveoli suggested pulmonary oedema in all cases, but the changes were more severe in total anomalous pulmonary venous return of the infradiaphragmatic type than in that of the supradiaphragmatic type. In all cases microscopical examination gave an impression of alveolar wall thickening. Only in cases of the infradiaphragmatic type was this confirmed by finding, on microscopical pointcounting, an increased proportion of alveolar wall tissue. The structural changes in the pulmonary circulation are summarised in Table 3.

\section{Arterial size}

Arterial size varied with the site of pulmonary venous drainage. In all cases with supradiaphragmatic drainage the lumen diameter of preacinar arteries was increased and that of the intra-acinar arteries at terminal bronchiolus level. The dilated vessels were also tortuous. In cases with infradiaphragmatic drainage both pre- and intra-acinar arteries were of normal size; tortuosity was seen in only one case (case 6) and then it was slight. 
Table 3 Summary of pathological findings

\begin{tabular}{|c|c|c|c|c|c|c|c|}
\hline & $\begin{array}{l}\text { Case } \\
\text { no. }\end{array}$ & $\begin{array}{l}\text { Arterial size } \\
\text { Preacinar }\end{array}$ & Intra-acinar & $\begin{array}{l}\text { Microscopical } \\
\text { arterial no. }\end{array}$ & $\begin{array}{l}\text { Arterial } \\
\text { wall } \\
\text { thickness }\end{array}$ & $\begin{array}{l}\text { Extension } \\
\text { of muscle }\end{array}$ & $\begin{array}{l}\text { Venous } \\
\text { wall } \\
\text { thickness }\end{array}$ \\
\hline $\begin{array}{l}\text { Supradiaphragmatic total anomalous } \\
\text { pulmonary venous return } \\
\text { Infradiaphragmatic total anomalous } \\
\text { pulmonary venous return }\end{array}$ & $\begin{array}{l}1 \\
2 \\
3 \\
4 \\
5 \\
6 \\
7 \\
8 \\
9\end{array}$ & $\begin{array}{l}\uparrow \\
\uparrow \\
\uparrow \\
\uparrow \\
\mathbf{N} \\
\mathbf{N} \\
\mathbf{N} \\
\mathbf{N}\end{array}$ & $\begin{array}{c}\mathbf{N} \\
\mathbf{N} \\
\uparrow \\
\uparrow \\
\mathbf{N} \\
\mathbf{N} \\
\mathbf{N} \\
\mathbf{N} \\
\mathbf{N}\end{array}$ & $\begin{array}{c}\mathbf{N} \\
\mathbf{N} \\
\mathbf{N} \\
\downarrow \\
\mathbf{N} \\
\mathbf{N} \\
\mathbf{N} \\
\mathbf{N} \\
\mathbf{N}\end{array}$ & $\begin{array}{l}\uparrow \\
\uparrow \\
\uparrow \\
\uparrow \\
\uparrow \\
\uparrow\end{array}$ & $\begin{array}{l}\uparrow \\
\uparrow \uparrow \\
\uparrow \uparrow \\
\uparrow \\
\uparrow\end{array}$ & $\begin{array}{l}\uparrow \\
\uparrow \\
\uparrow \\
\uparrow \\
\uparrow \\
\uparrow\end{array}$ \\
\hline
\end{tabular}

$\mathrm{N}$ Normal. $\quad \uparrow$ Increased above normal. $\uparrow \uparrow$ Greater increase than $\uparrow$.

Number of intra-acinar arteries

Microscopically the number of arteries and of alveoli per unit area of lung was normal in all except case 4 where the number of arteries was reduced and consequently the alveolar/arterial ratio was increased. The haze on the arteriogram, caused by filling of small peripheral arteries, was of normal density in all except case 4 where it was reduced.

\section{Assessment of arterial muscularity}

All 9 cases of total anomalous pulmonary venous return were similar in that arterial muscularity was increased as judged by an increase in wall thickness (Fig. 1) and by extension of muscle into smaller and more peripheral arteries than normal (Fig. 2).
Arteries of diameter less than $250 \mu \mathrm{m}$

In all cases of total anomalous pulmonary venous return the wall thickness of arteries less than $250 \mu \mathrm{m}$ in diameter was greater than is normal for age (Fig. 1) or, with the exception of the youngest child (case 6), than is normally seen during fetal life. The degree of increased muscularity was significantly greater in the supradiaphragmatic type than in the infradiaphragmatic type, with the exception of vessels smaller than $50 \mu \mathrm{m}$ in diameter in which muscularity was greater in cases with infradiaphragmatic drainage. This greater increase in muscularity of the smallest arteries may reflect a longer duration of severe pulmonary venous hypertension in the latter than in cases with supradiaphragmatic drainage.

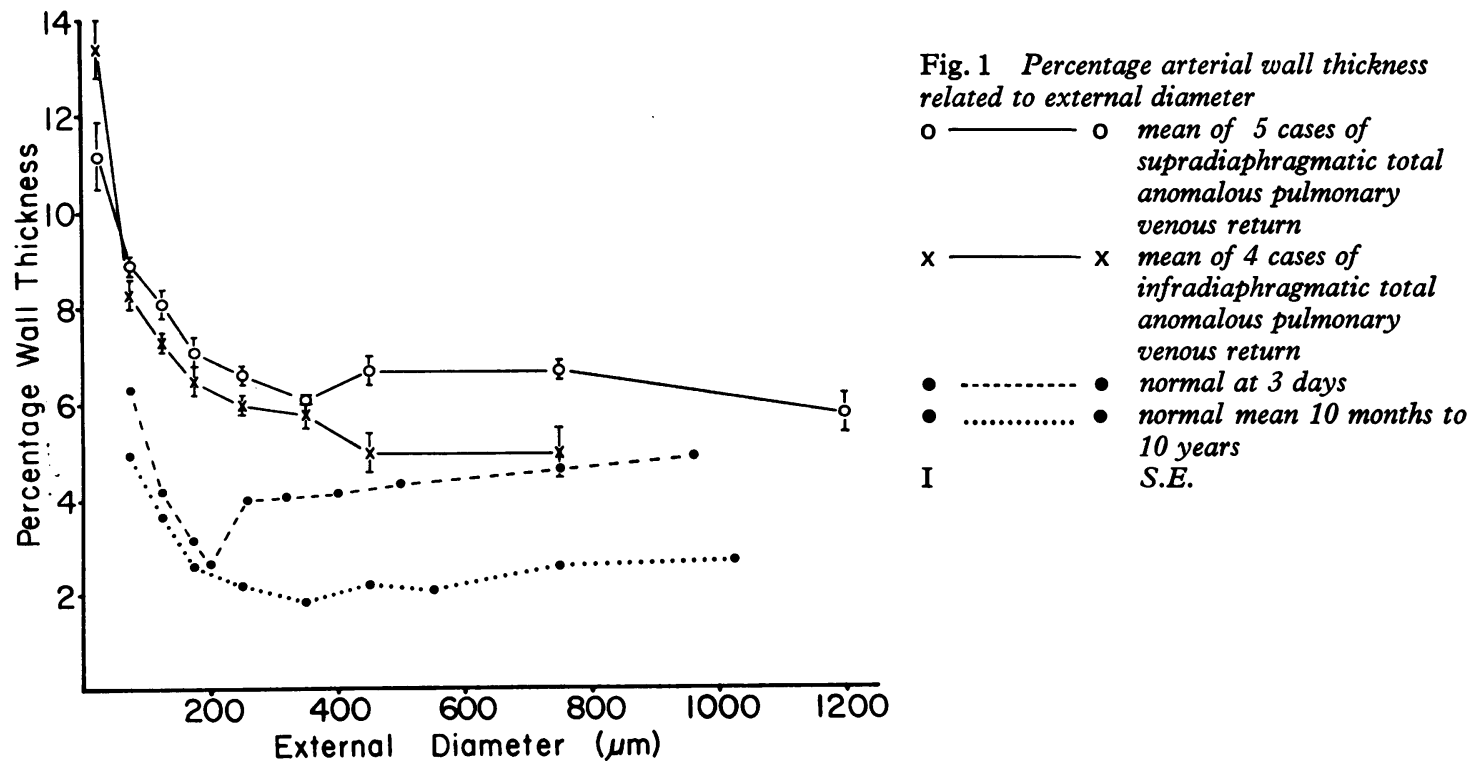

Fig. 1 Percentage arterial wall thickness related to external diameter supradiaphragmatic total anomalous pulmonary mous return infradiaphragmatic total anomalous pulmonary 10 years S.E. 


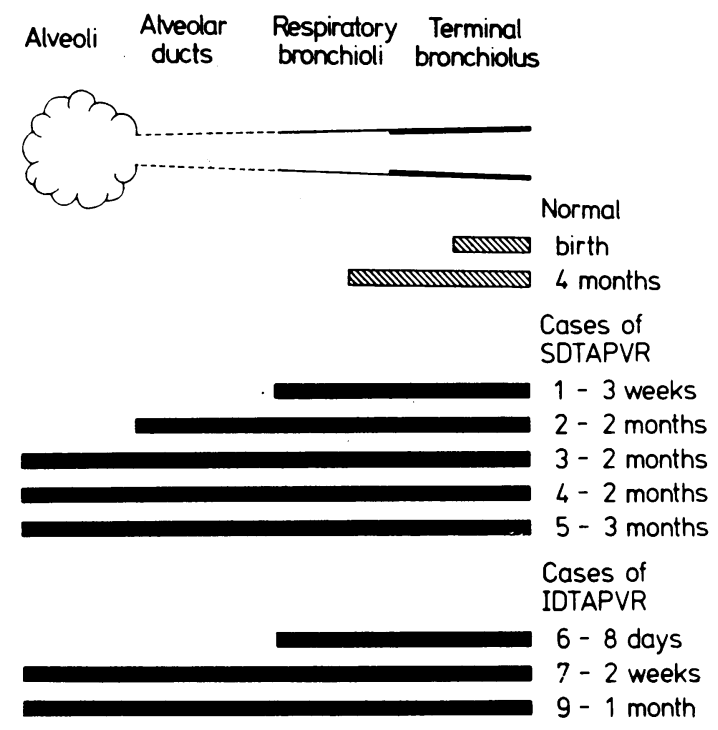

Fig. 2 Diagram illustrating extension of muscle along the intra-acinar arteries; the end of the black line corresponds to the position along the pathway at which the majority of arteries have a partially muscular wall. $S D T A P V R=$ supradiaphragmatic total anomalous venous return. IDTAPVR=infradiaphragmatic total anomalous pulmonary venous return

All cases of total anomalous pulmonary venous return showed a decrease in the proportion of small arteries having a non-muscular wall. At about 2 months of age, in the normal lung 92 to 97 per cent of arteries between 25 and $50 \mu \mathrm{m}$ in diameter are non-muscular whereas, in case 4 for example, it was only 10 per cent of vessels in this size group.

\section{Arteries of diameter more than $250 \mu \mathrm{m}$}

These arteries, like the smaller vessels, showed a greater wall thickness than is normally seen during fetal life except in case 6 . Wall thickness was significantly greater in cases of venous return of supradiaphragmatic type than in those of infradiaphragmatic type, possibly because of their greater age.

The structure of arteries accompanying peripheral airways showed considerable extension of muscle along the arterial pathway (Fig. 2). At birth, in the normal lung few arteries within the acinus have a muscular coat; it is during childhood that muscle gradually extends along the arterial pathway reaching alveolar wall vessels by late adolescence (Hislop and Reid, 1973a). In the present series of total anomalous pulmonary venous return, in all but the two youngest cases at least 80 per cent of arteries accompanying respiratory bronchioli were entirely muscularised. Even by the fourth month of life, in the normal lung only 67 per cent of arteries at this level are muscularised (Hislop, 1971). In all cases with total anomalous pulmonary venous return many arteries within the alveolar wall had a completely muscular coat. The degree of extension varied in different cases and was not related to the site of pulmonary venous return.

The muscle cells in the most peripheral vessels were mature, as judged by their staining characteristics, even in the patient 8 days old at death.

\section{Vein size and wall thickness}

Findings were similar in all four available venograms -3 from cases of supradiaphragmatic type and one from a case of infradiaphragmatic type. Throughout their length the venous pathways were obviously dilated, unlike the arterial pathways where dilatation was most pronounced proximally. In both venograms and arteriograms the severity of dilatation was similar in upper and lower lobe vessels.

In all 4 cases vein wall muscularity was increased as judged by an increase in vein wall thickness and by the presence of muscle in smaller veins than is normal. Considerable increase in vein wall thickness was also obvious in the uninjected specimens. In all but the 2 youngest cases (cases 1 and 6 ) elastic fibres were increased and a well-defined external elastic lamina was present, the appearance of 'arterialization' of veins (Wagenvoort, 1970).

In all the cases the pulmonary capillaries were considerably engorged.

\section{II : STRUCTURAL CHANGES IN HEART}

In all 9 cases visceroatrial situs was normal, there was a d-bulboventricular loop and the great vessels were normally related. In 8 out of 9 cases the left ventricle had developed normally, as judged by measurements of the length of the inflow and outflow tracts. In case 9 the left ventricle was abnormally small and its weight, even when added to that of the septum, was less than that of a normal fetus at term (Hislop and Reid, 1972a). In all 9 cases the free wall of the left ventricle was of normal thickness.

The main structural changes were in the right ventricle, which was dilated and hypertrophied in cases of total anomalous pulmonary venous return to the supradiaphragmatic site, but not in those with drainage to the infradiaphragmatic site; the septum was also hypertrophied but, again, only in cases of venous return to the supradiaphragmatic site. 
Structural changes in total anomalous pulmonary venous return to the supradiaphragmatic site In all these cases dilatation of the right ventricle was shown by an increase in length of both inflow and outflow tracts. The mean length of the outflow tract measured $40.8 \mathrm{~mm}$ whereas the mean normal value during the first year of life is only $33.33 \mathrm{~mm}$ (de la Cruz et al., 1960). In all cases, the right ventricle became more spherical in shape, so resembling a left rather than a right ventricle. Cut in transverse section, the entire circumference of the right ventricle was increased in thickness, the increase in muscularity affecting the septum as well as the free wall of the ventricle (Fig. 3).

Although an increase in wall thickness is less reliable than an increase in muscle weight as a measure of ventricular hypertrophy, in cases of supradiaphragmatic type this was considerably increased, varying between 5 and $8 \mathrm{~mm}$, whereas the upper limit of normal, even at 1 year of age, is only $3.19 \mathrm{~mm}$ (de la Cruz et al., 1960).

In all cases of total anomalous pulmonary venous return to the supradiaphragmatic site the weight of both the free wall of the right ventricle and of the septum was increased (Table 4), leading to an increased total heart weight of between 30.3 and $50 \mathrm{~g}$, the upper limit of normal being $23 \mathrm{~g}$ during the first 3 months of life (Coppoletta and Wolbach, 1933). The septum weighed more than $9.5 \mathrm{~g}$ in 4 out of 5 children with this anomaly all of whom were less than 3 months of age, whereas in normal children from birth to 5 years Roessle and Roulet (1932) reported a mean septal weight of $11 \mathrm{~g}$. In all cases of total anomalous pulmonary venous

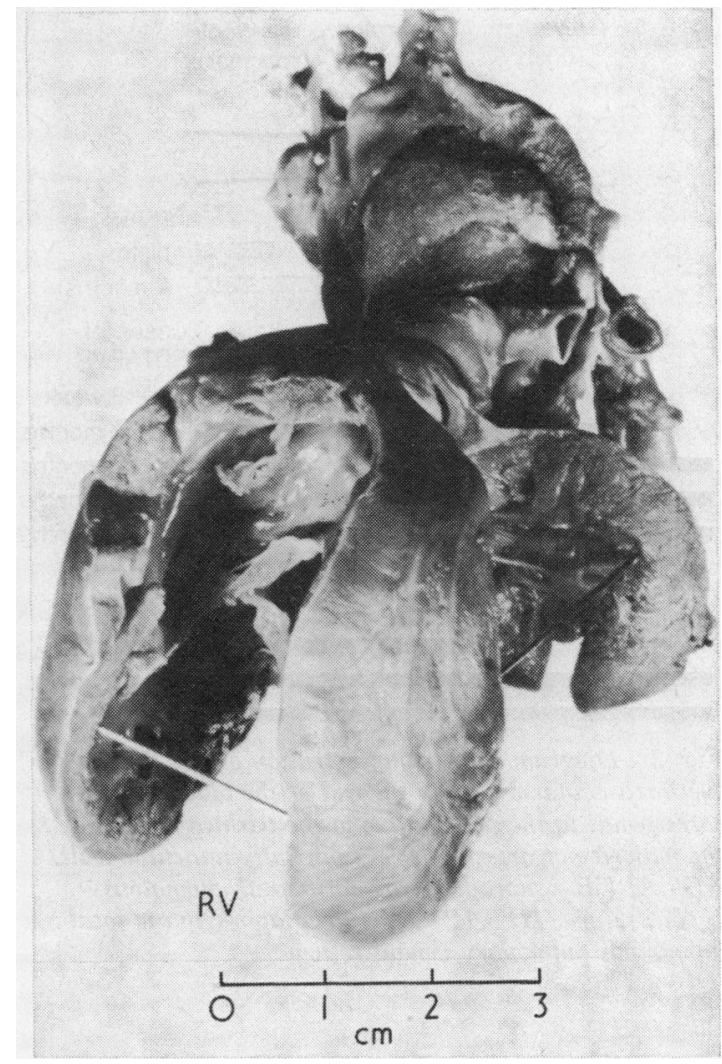

Fig. 3 The heart in supradiaphragmatic total anomalous pulmonary venous return (case 4) showing severe dilatation and hypertrophy of the right ventricle (RV) in the presence of a normally developed left ventricle

Table 4 Morphological findings in heart : weights of right and left ventricular free wall and septum $(g) . R a t i o \frac{L V+S}{R V}$

\begin{tabular}{|c|c|c|c|c|c|c|c|}
\hline & $\begin{array}{l}\text { Case } \\
\text { no. }\end{array}$ & $R V$ & $L V$ & Septum & $L V+S$ & $\frac{L V+S}{R V}$ & \\
\hline $\begin{array}{l}\text { Supradiaphragmatic total anomalous } \\
\text { pulmonary venous return } \\
\text { Infradiaphragmatic total anomalous } \\
\text { pulmonary venous return }\end{array}$ & $\begin{array}{l}1 \\
2 \\
3 \\
4 \\
5 \\
6 \\
7 \\
8 \\
9\end{array}$ & $\begin{array}{r}12 \cdot 213 \\
18 \cdot 336 \\
20 \cdot 755 \\
18 \cdot 146 \\
16 \cdot 808 \\
5 \cdot 267 \\
4 \cdot 395 \\
5 \cdot 553 \\
9 \cdot 748\end{array}$ & $\begin{array}{l}3 \cdot 438 \\
4 \cdot 421 \\
6 \cdot 475 \\
5 \cdot 560 \\
5 \cdot 688 \\
2 \cdot 446 \\
3 \cdot 575 \\
3 \cdot 276 \\
2 \cdot 446\end{array}$ & $\begin{array}{r}5 \cdot 891 \\
10 \cdot 118 \\
13 \cdot 280 \\
12 \cdot 236 \\
9 \cdot 597 \\
3 \cdot 212 \\
5 \cdot 081 \\
3 \cdot 284 \\
3 \cdot 880\end{array}$ & $\begin{array}{r}9 \cdot 329 \\
14 \cdot 539 \\
19 \cdot 755 \\
16.796 \\
14 \cdot 285 \\
5.658 \\
8 \cdot 656 \\
6 \cdot 560 \\
6 \cdot 326\end{array}$ & 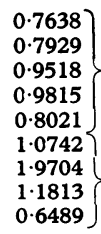 & $\left\{\begin{array}{l}m=0.8584 \\
m=1.2187\end{array}\right.$ \\
\hline $\begin{array}{l}\text { Normal values } \\
\text { (1) Fetus at term } \\
\text { (2) Stillborn } \\
10 \text { months } \\
\text { (3) } 1 \text { to } 5 \text { years }\end{array}$ & & $\begin{array}{l}\text { Range } \\
5 \cdot 823-5 \cdot 6 \\
5 \cdot 6 \\
7 \cdot 1\end{array}$ & & 11 & \multicolumn{3}{|c|}{$\begin{array}{lc}\text { Range during fetal life } \\
6 \cdot 355-6 \cdot 7 & 1 \cdot 06-2 \cdot 0 \\
6 \cdot 67 & 1 \cdot 2 \\
20 \cdot 5 & 2 \cdot 89\end{array}$} \\
\hline
\end{tabular}

(1) Hislop (1971); (2) Davies and Reid (1970); (3) Roessle and Roulet (1932). 
return to the supradiaphragmatic site, therefore, the weight of the left ventricle plus septum $(L V+S)$ was greater than normal because of septal hypertrophy and even despite this the ratio of $L V+S / R V$ was lower than that of a normal fetus at term, indicating the severe degree of hypertrophy of the free wall of the right ventricle.

\section{Structural changes in total anomalous pulmonary venous return to the infradiaphragmatic site}

In 3 out of 4 cases (cases 6,7 , and 8) the right ventricle had a normal appearance, seeming neither dilated nor hypertrophied, an impression confirmed by measurements of cavity size and weight (Table 4). In these cases the free wall of the right ventricle was slightly thicker than normal, measuring between 4 and $6 \mathrm{~mm}$ (normal at 1 year of age= $3.19 \mathrm{~mm}$, de la Cruz et al., 1960), and suggesting some increase in ventricular muscle mass. In these 3 cases the weight of the free wall of the right ventricle, that of the septum and of $L V+S$ was normal, as was the ratio of $L V+S / R V$. Thus, in this anomaly there is little evidence of hypertrophy of the right ventricle during the first month of life.

In contrast, in case 9 where the left ventricle was abnormally small, the right ventricle was hypertrophied. The free wall of the right ventricle was increased in both thickness and in weight but, unlike cases with supradiaphragmatic drainage, the weight of the septum was normal. The ratio of $\mathrm{LV}+\mathrm{S} / \mathrm{RV}$ was reduced, confirming the presence of right ventricular hypertrophy.

In summary, in total anomalous pulmonary venous return pulmonary arterial and venous branching patterns were normal. At the lung periphery the arteries and alveoli appeared to have multiplied normally, arterial number being reduced in only one case (case 4). The lumen diameter of pre- and intra-acinar arteries was increased in cases of total anomalous pulmonary venous return of supradiaphragmatic type. In both supra- and infradiaphragmatic types of total anomalous pulmonary venous return arterial muscularity was increased, as shown by increase in wall thickness and by extension of muscle into smaller and more peripheral arteries than is normal, and both these changes tended to increase with age. In both types, also, vein wall thickness was increased and, in all but the two youngest children, the veins were 'arterialised'.

In the heart the left ventricle was of normal size in 8 out of 9 cases (in the other it was abnormally small). In cases with the supradiaphragmatic type the right ventricle was dilated and hypertrophied and the septum had hypertrophied with the free wall of the right ventricle, appearing to have behaved as part of the right ventricle, not of the left as in the normal infant.

\section{Discussion}

In these cases of total anomalous pulmonary venous return the pathological findings could be related to the clinical features. Patients with the supradiaphragmatic type had survived longer, and in these patients the clinical features suggested that a large left-to-right shunt had preceded the development of severe obstruction to pulmonary venous return. By radiography the pulmonary arteries were shown to be dilated, and pathological examination confirmed this and also showed dilatation of the right ventricle. A longer duration of pulmonary hypertension in these patients might also explain why right ventricular and septal hypertrophy were severe in this group and not in those with the infradiaphragmatic type.

\section{Comparison of present pathological findings with previous reports}

In the present study, injection of a radio-opaque medium into the pulmonary vessels and the quantitative analysis of the structural findings has been applied for the first time in total anomalous pulmonary venous return, and has increased our knowledge of the structural changes in the pulmonary circulation in this condition.

From the arteriogram it has been possible to show a normal intrapulmonary arterial and venous branching system at preacinar level: within the acinus, injection enables the arterial and venous systems to be separately identified microscopically, and a normal distribution of both systems has been revealed at this level also. Because the vessels had been distended before fixation, precise measurement of vessel size and number was possible. Since the same techniques have previously been used to study the normal pre- and postnatal development of the pulmonary circulation (Hislop and Reid, 1972b, 1973a), normal values were available for comparison, an essential requirement in the first months of life when the lung is developing rapidly.

Using these techniques, we detected an increase in pulmonary arterial muscle, at an earlier age of 8 days, than Lucas et al. (1963) who, using uninjected material, could not always show increased muscularity until after the first month of life. By relating the structure of an artery to both its size and its position along the arterial pathway, abnormal muscularisation of the intra-acinar arteries was also shown. The veins also were hypertrophied, their percentage wall thickness being between 3 and 
6 per cent compared with a normal mean value of approximately 1 per cent (Hislop and Reid, 1973b). This result is not dissimilar from that obtained by Samuelson et al. (1970) who, in uninjected material, reported a mean value of $5 \cdot 1$ per cent for 5 cases of total anomalous pulmonary venous return: they gave 3.3 per cent as the mean value of a series of normal lungs.

Our findings differed from those of Wagenvoort et al. (1972) in that we did not show any precapillary anastomoses between either the pulmonary and bronchial arterial systems or between pulmonary and bronchial veins in these cases of total anomalous pulmonary venous return with pulmonary venous obstruction. This may be explained by the fact that the cases studied by Wagenvoort et al. (1972) were of premature closure of the foramen ovale in utero, a condition in which pulmonary venous hypertension is present before birth, which seems unlikely to occur in most patients with total anomalous pulmonary venous return. Differences in technique may also be important since these authors have also shown similar precapillary anastomoses in the normal newborn lung which Hislop and Reid (1972b) were unable to do, using the same injection method as in the present study. On the other hand, the present technique has been used to show peripheral arteriovenous communications in the lungs of patients dying with cirrhosis of the liver (Berthelot et al., 1966).

\section{Time of onset of obstruction to pulmonary venous return}

In the present study the pathological findings suggest that there is no significant obstruction to the return of pulmonary venous blood in utero. The preacinar arterial and venous branching systems are normal, but since these vessels are usually present by the 16th week of intrauterine life (Hislop and Reid, 1972b) their development is not likely to be affected. In contrast, the multiplication of intra-acinar arteries begins later in intrauterine life and, in some conditions, when the pulmonary circulation is disturbed during fetal life, has been shown to be abnormal at birth. In the hypoplastic left heart syndrome, where pulmonary arterial pressure is probably abnormally high during fetal life, an increase in arterial number was shown (Haworth and Reid, 1976). The normal number of intra-acinar arteries found in total anomalous pulmonary venous return suggests that a significant increase in pulmonary arterial pressure did not occur in utero. Moreover, the increase in arterial wall thickness was less severe than that seen in the hypoplastic left heart syndrome. Furthermore, in the youngest patient with total anomalous pul- monary venous return, arterial wall thickness was lower than that seen in the normal fetus at term, suggesting that the reduction in wall thickness of small arteries that normally occurs in the first few days of life, had also occurred here (Hislop and Reid, 1973a). Even the mature appearance of the muscle cells in the intra-acinar arteries, seen in the youngest child at 8 days of age, does not suggest that obstruction to pulmonary venous return necessarily developed before birth. In the experimental animal the 'new' muscle cells appearing at this level in the lung acquire mature staining characteristics after only five days of hypoxia (Hislop and Reid, 1976).

Thus, it seems likely that the pulmonary circulation was functionally normal in utero. At birth, with the onset of respiration, pulmonary blood flow increases: and in total anomalous pulmonary venous return the subsequent course of events is determined by several factors that include the length and diameter of the common pulmonary vein, the degree of obstruction, and the size of the foramen ovale (Burchell, 1956; Serratto et al., 1967) and in the infradiaphragmatic type, by whether or not the ductus venosus is patent. In cases with the infradiaphragmatic type obstruction usually becomes severe soon after birth and in the supradiaphragmatic type it usually develops later. In the present series the mean age at death for the infradiaphragmatic group was 20 days, whereas for the supradiaphragmatic group it was 55 days. The finding here of preacinar arterial dilatation in cases with the supradiaphragmatic type of venous return, even in those dying at less than 1 month of age, suggests that this type is usually associated with an abnormally high flow for at least some time after birth.

\section{MECHANISMS RESPONSIBLE FOR STRUCTURAL} CIRCULATORY CHANGES

The haemodynamic changes in the pulmonary circulation after birth, before the development of obstruction to pulmonary venous return, are obviously unknown but what might have happened can be argued from the structural changes seen in the present study. An arterial wall thickness below the normal fetal level in the youngest child, one with the supradiaphragmatic type, suggests that after birth thinning of the arterial wall, known as 'regression of fetal muscle', did occur in these infants. A secondary increase in muscularity then developed as obstruction to pulmonary venous return developed. In contrast, in the infradiaphragmatic group, the early onset of obstruction probably means incomplete regression of fetal muscularity. 
In most infants dying with congenital heart disease, the structural evidence of a normal postnatal reduction in wall thickness is superseded by a secondary increase in muscularity, and it is now known that an increase in pulmonary arterial muscle can occur rapidly. In injected material it is possible to distinguish these 'new' muscle cells at the periphery of the arterial pathway by finding muscle in arteries further along the arterial pathway than is normal. Previously, in the infant lung, the speed with which muscle can hypertrophy has probably been underestimated, and too often excessive muscularity has been attributed to persistence of the fetal pattern.

An increase in arterial muscularity would raise pulmonary vascular resistance and reduce pulmonary blood flow. In the present series, as medial hypertrophy developed in cases of total anomalous pulmonary venous return of the supradiaphragmatic type, pulmonary blood flow fell (Fig. 4). In total anomalous pulmonary venous return pulmonary blood flow is not, however, solely dependent on resistance as in ventricular septal defect (Rudolph, 1974; Hoffman and Rudolph, 1965). Right ventricular filling must increase as the size of the foramen ovale decreases and thus pulmonary blood flow can increase despite an already raised pulmonary vascular resistance, and this Rudolph (1974) suggests makes regression of pulmonary arterial muscularity particularly susceptible to delay in total anomalous pulmonary venous return.

Medial hypertrophy of the vein wall was severe in all cases. The severity of venous medial hypertrophy was greater the thicker the arterial muscle coat, as has previously been seen in ventricular septal defect (Hislop et al., 1975). The presence of muscle in veins smaller than $50 \mu \mathrm{m}$ in diameter indicates peripheral extension of muscle along the venous pathway. Thus, increase in thickness of the vein or arterial wall muscle is each associated with peripheral extension of muscle along the particular pathway. In total anomalous pulmonary venous return it is not surprising to find increased muscularity of the pulmonary veins associated with obstruction to pulmonary venous return, but similar changes can occur in the presence of a high pulmonary blood flow with pulmonary arterial hypertension, as in a ventricular septal defect (Hislop et al., 1975), suggesting that venous medial hypertrophy is a response to either pulmonary arterial or venous hypertension.

In all cases in the present series, the capillaries were considerably engorged. Ferencz and Dammann (1957) commented that capillary engorgement was seen only in those congenital cardiac malformations

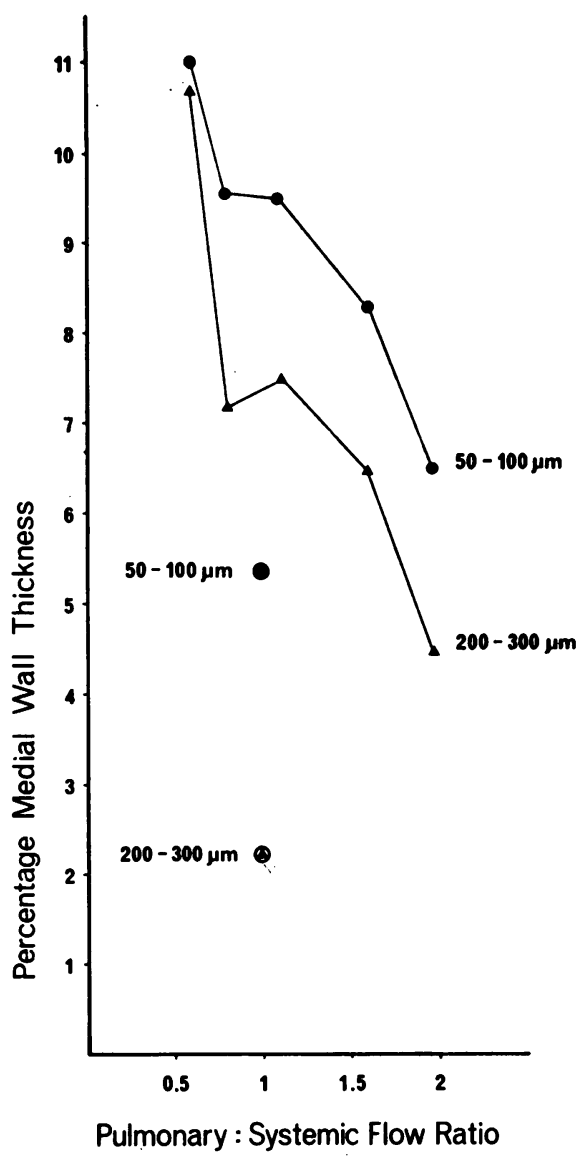

Fig. 4 Percentage arterial wall thickness in vessels of different sizes, related to the pulmonary: systemic flow ratio in 5 cases of supradiaphragmatic total anomalous pulmonary venous return, showing a progressive increase in muscularity as pulmonary blood flow falls 8\}Normal values

giving rise to severe pulmonary venous hypertension.

Whereas all 9 cases in the present series had pulmonary hypertension, in only 1 case was the number of intra-acinar arteries reduced. A reduction has recently been reported in pulmonary hypertension resulting from a variety of causes: primary pulmonary hypertension (Anderson et al., 1973), cor pulmonale in cystic fibrosis and chronic bronchitis (Ryland and Reid, 1975; Semmens and Reid, 1974), and experimental pulmonary hypertension (Hislop and Reid, 1974, 1976). In these conditions, reduction in arterial number is 
usually the result of loss of arteries that were once present and it occurs rapidly. In the experimental rat it is detectable after only 5 days' exposure to hypoxia (Hislop and Reid, 1976). It seems from the present series that pulmonary venous hypertension, unlike arterial hypertension, is not associated, at least initially, with arterial loss. Why reduction in arterial number should have occurred in this particular case is not clear, though this patient did have a higher pulmonary vascular resistance than any other case in the series suggesting a greater degree of obstruction, and, possibly since he had reached 2 months of age, of longer duration.

\section{PATHOLOGICAL CHANGES IN THE HEART}

Our findings suggest that in most, though not all, cases of total anomalous pulmonary venous return the left ventricle is normally developed. Leachman et al. (1969) reported a normal development of the left ventricle in all 58 cases of their series of total anomalous pulmonary venous return. The exception in our series is important because, in such a case, underdevelopment of the left ventricle may, as suggested by Mustard et al. (1968), be a barrier to corrective surgery.

The dominance of the right ventricle probably represents a persistence of the fetal state because obstruction to pulmonary venous return developed soon after birth. In all cases of total anomalous pulmonary venous return of supradiaphragmatic type the weight of the right ventricle was greater than is seen during normal fetal life, suggesting additional postnatal development of muscle. Findings in the present series indicate the rapidity with which the right ventricle can hypertrophy in the newborn and young infant, the youngest patient with the supradiaphragmatic type had developed severe hypertrophy by 21 days of age.

During fetal life Harvey (1628) noted the structural similarity of the two ventricles, likening them to the 'double kernels of a nut'. After birth growth of the left ventricle normally outstrips that of the right and the septum grows with this ventricle. Findings in the present series, however, show that when pulmonary hypertension develops at or soon after birth the septum grows with the right ventricle and their growth together overtakes that of the left. Why, in the one case of underdevelopment of the left ventricle, the septum did not hypertrophy is not clear but it may be that the septum behaved as part of the left ventricle, partaking in the underdevelopment of this chamber.

CLINICAL IMPLICATIONS OF STRUCTURAL CHANGES IN THE LUNGS

The rapid rate at which both arterial and venous medial hypertrophy develop, together with the reduction in arterial number in one case in the series, suggests that surgical correction should be attempted when an infant with total anomalous pulmonary venous return first presents with severe pulmonary hypertension. Delay in treatment will lead to increase in muscularity of the peripheral circulation. In a recent review of 125 patients with total anomalous pulmonary venous return, Wukasch et al. (1975) found that survival was related to the preoperative level of pulmonary vascular resistance. These workers found that atrial septostomy was effective only temporarily and recommended that it never be used in the presence of pulmonary venous obstruction. Our findings support this, since, if relief of pulmonary hypertension were only partial, it would not allow regression of any medial hypertrophy which had already developed, nor prevent its advance. Indeed, in one case studied by the authors in whom only partial relief of obstruction was achieved by 'corrective' surgery at 2 days of age, the wall thickness in arteries of all sizes at time of death at 3 months of age was greater than during normal fetal life and greater than in any case in the present series.

Recent studies in infants with ventricular septal defect have shown that the lung does not develop normally in the presence of severe pulmonary hypertension, since the intra-acinar arteries stay small and fail to multiply normally (personal observation), again emphasising the need for early operation. In early infancy surgical mortality is high, and Wukasch et al. (1975) recommended that operation be delayed until after 6 months of age. At present, the optimal time for corrective surgery must be a compromise between the risk of operation and of impaired development of the pulmonary circulation.

We wish to thank Dr. K. F. W. Hinson who kindly allowed us to study the specimens, Dr. M. C. Joseph, Dr. E. A. Shinebourne, Mr. M. Paneth and Mr. S. Lennox for access to the clinical results of their cases, and Dr. G. A. H. Miller who catheterised these patients.

\section{References}

Anderson, E. G., Simon, G., and Reid, L. (1973). Primary and thromboembolic pulmonary hypertension. A quantitative pathological study. Fournal of Pathology, 110, 273-293.

Berthelot, P., Walker, J. G., Sherlock, S., and Reid, L. (1966). Arterial changes in the lungs in cirrhosis of the liver-lung spider nevi. New England fournal of Medicine, 274, 291-298.

Bonham-Carter, R. E., Capriles, M., and Noe, Y. (1969). Total anomalous pulmonary venous drainage; a clinical and anatomical study of 75 children. British Heart fournal, 31, 45-51. 
Burchell, H. B. (1956). Total anomalous pulmonary venous drainage: clinical and physiologic patterns. Mayo Clinic Proceedings, 31, 161-167.

Burroughs, J. T., and Edwards, J. E. (1960). Review: Total anomalous pulmonary venous connection. American Heart fournal, 59, 913-931.

Coppoletta, J. M., and Wolbach, S. B. (1933). Body length and organ weights of infants and children; study of body length and normal weights of the more important vital organs of the body between birth and 12 years of age. American fournal of Pathology, 9, 55-70.

de la Cruz, M. V., Anselmi, G., Romero, A., and Monroy, G. (1960). A qualitative and quantitative study of the ventricles and great vessels of normal children. American Heart fournal, 60, 675-690.

Davies, G., and Reid, L. (1970). Growth of the alveoli and pulmonary arteries in childhood. Thorax, 25, 669-681.

Delisle, G., Ando, M., Calder, A. L., Zuberbuhler, J. R., Rochenmacher, S., Alday, L. E., Mangini, O., van Praagh, S., and van Praagh, R. (1976). Total anomalous pulmonary venous connection: report of 93 autopsied cases with emphasis on diagnostic and surgical considerations. American fournal of Cardiology. (In the press.)

Dunnill, M. S. (1962). Quantitative methods in the study of pulmonary pathology. Thorax, 17, 320-328.

Ferencz, C., and Dammann, J. F. (1957). The significance of the pulmonary vascular bed in congenital heart disease. V. Lesions of the left side of the heart causing obstruction of the pulmonary venous return. Circulation, 16, 10461056.

Fulton, R. M., Hutchinson, E. C., and Jones, A. M. (1952). Ventricular weight in cardiac hypertrophy. British Heart fournal, 14, 413-420.

Gathman, G. E., and Nadas, A. S. (1970). Total anomalous pulmonary venous connection: clinical and physiologic observations in 75 pediatric patients. Circulation, 42, 143-154.

Harvey, W. (1628). Exercitatio Anatomica de Motu Cordis. Fitzer Frankfort. (English translation, 1957.) Movement of the Heart and Blood in Animals. Translated from the original Latin by K. J. Franklin. Blackwell, Oxford.

Hastreiter, A. R., Paul, M. H., Molthan, M. E., and Miller, R.A. (1962). Total anomalous pulmonary venous connection with severe pulmonary venous obstruction. Circulation, 25, 916-928.

Haworth, S. G., and Reid, L. (1976). A quantitative structural study of the pulmonary circulation in the newborn with congenital heart disease. Submitted for publication.

Hislop, A. A. (1971). The fetal and childhood development of the pulmonary circulation and its disturbance in certain types of congenital heart disease. Ph.D. Thesis, University of London.

Hislop, A., and Reid, L. (1970). New pathological findings in emphysema of childhood. 1. Polyalveolar lobe with emphysema. Thorax, 25, 682-690.

Hislop, A., and Reid, L. (1972a). Weight of the left and right ventricle of the heart during fetal life. Fournal of Clinical Pathology, 25, 534-536.

Hislop, A., and Reid, L. (1972b). Intrapulmonary arterial development during fetal life-branching pattern and structure. Fournal of Anatomy, 113, 35-48.

Hislop, A., and Reid, L. (1973a). Pulmonary arterial development during childhood-branching pattern and structure. Thorax, 28, 129-135.

Hislop, A., and Reid, L. (1973b). Fetal and childhood development of the intrapulmonary veins in man-branching pattern and structure. Thorax, 28, 313-319.

Hislop, A., and Reid, L. (1974). Arterial changes in Crotalaria spectabilis-induced pulmonary hypertension in rats. British fournal of Experimental Pathology, 55, 153-163.

Hislop, A., and Reid, L. (1976). New findings in pulmonary arteries of rats with hypoxia-induced pulmonary hypertension. British Fournal of Experimental Pathology. (In the press.)

Hislop, A., Haworth, S. G., Shinebourne, E. A., and Reid, L. (1975). Quantitative structural analysis of pulmonary vessels in isolated ventricular septal defect in infancy. British Heart fournal, 37, 1014-1021.

Hoffman, J. I. E., and Rudolph, A. M. (1965). The natural history of ventricular septal defects in infancy. American fournal of Cardiology, 16, 634-653.

Johnson, A. L., Wigglesworth, F. W., Dunbar, J. S., Siddoo, S., and Grajo, M. (1958). Infradiaphragmatic total anomalous pulmonary venous connection. Circulation, 17, 340347.

Kauffman, S. L., Ores, C. N., and Andersen, D. H. (1962). Two cases of total anomalous pulmonary venous return of the supracardiac type with stenosis simulating infradiaphragmatic drainage. Circulation, 25, 376-382.

Leachman, R. D., Cooley, D. A., Hallman, G. L., Simpson, J. W., and Pear, W. E. (1969). Total anomalous pulmonary venous return: correlation of hemodynamic observations and surgical mortality in 58 cases. Annals of Thoracic Surgery, 7, 5-12.

Lucas, R. V., Jr., Anderson, R. C., Amplatz, K., Adams, P., Jr., and Edwards, J. E. (1963). Congenital causes of pulmonary venous obstruction. Pediatric Clinics of North America, 10, 781-836.

Millard, F. J. C. (1965). The development and the electrocardiographic diagnosis of right ventricular hypertrophy in chronic lung disease. M.D. Thesis, University of London.

Miller, W. W., Rashkind, W. J., Miller, R. A., Hastreiter, A. R., Green, E. W., Golinko, R. J., and Young, D. (1967). Total anomalous pulmonary venous return: effective palliation of critically ill infants by balloon atrial septotomy (abstract). Circulation, 35-36, Suppl. II, 189.

Moss, A. J., and Adams, F. H. (1968). (Eds.) Heart Disease in Infants, Children and Adolescents, p. 205. Williams and Wilkins, Baltimore.

Mustard, W. T., Keon, W. J., and Trusler, G. A. (1968), Transposition of the great arteries and transposition of the lesser veins. II. Transposition of the lesser veins (T.A.P.V.D.). Progress in Cardiovascular Diseases, 11, 145155.

Roessle, R., and Roulet, F. (1932). Mass und Zahl in der Pathologie, p. 144. J. Springer, Berlin and Vienna.

Rudolph, A. M. (1974). Congenital Diseases of the Heart. Year Book Medical Publishers, Chicago.

Ryland, D., and Reid, L. (1975). The pulmonary circulation in cystic fibrosis. Thorax, 30, 285-292.

Samuelson, A., Becker, A. E., and Wagenvoort, C. A. (1970). A morphometric study of pulmonary veins in normal infants and infants with congenital heart disease. Archives of Pathology, 90, 112-116.

Semmens, M., and Reid, L. (1974). Pulmonary arterial muscularity and right ventricular hypertrophy in chronic bronchitis and emphysema. British fournal of Diseases of the Chest, 68, 253-263.

Serratto, M., Bucheleres, H. G., Arevalo, F., Hastreiter, A. R., and Miller, R. A. (1967). Total anomalous pulmonary venous connection without obstruction: hemodynamic and prognostic importance of foramen ovale size. Circulation, 35-36, Suppl. II, 232.

Serratto, M., Bucheleres, H. G., Bicoff, P., Miller, R. A., and Hastreiter, A. R. (1968). Palliative balloon atrial septostomy for total anomalous pulmonary venous connection in infancy. Fournal of Pediatrics, 73, 734-739.

Wagenvoort, C. A. (1970). Morphologic changes in the intrapulmonary veins. Human Pathology, 1, 205-213.

Wagenvoort, C. A., Wagenvoort, N., and Becker, A. E. (1972). The effect of obstructed pulmonary venous blood flow on 
the development of alternative pathways in the lung. Requests for reprints to Professor Lynne Reid, fournal of Pathology, 107, 21-25.

Wukasch, D. C., Deutsch, M., Reul, G. J., Hallman, G. L., and Cooley, D. A. (1975). Total anomalous pulmonary venous return. Review of 125 patients treated surgically. Annals of Thoracic Surgery, 19, 622-633. Department of Experimental Pathology, Cardiothoracic Institute, Brompton Hospital, Fulham Road, London SW3 6HP. 